\title{
Analisis Kelayakan Usaha Budidaya Udang Vanname (Litopenaeus vannamei) di Keramba Jaring Apung Laut
}

\author{
Feasibility Analysis of Culture White Shrimp (Litopenaeus Vannamei) \\ at Sea Floating Net Cage (FNC) \\ Pindo Witoko $^{1^{*}}$, Ninik Purbosari ${ }^{*}$, dan Nuning Mahmudah Noor ${ }^{*}$ \\ ${ }^{1}$ Program Studi Budidaya Perikanan, Jurusan Peternakan \\ Politeknik Negeri Lampung, Jl. Soekarno-Hatta No 10. Rajabasa Bandar Lampung
}

\begin{abstract}
ABSTRAK
Udang vanname merupakan salah satu komoditas perikanan yang menjadi primadona. Pengembangan produksi udang vanname selain dapat dilakukan di tambak dapat juga dilakukan dengan menggunakan keramba jaring apung. Budidaya udang dilaut dengan keramba jaring apung merupakan salah satu alternatif budidaya udang yang ramah lingkungan dan berpotensi menjadi teknologi aplikatif budidaya udang dimasa mendatang. Penelitian ini bertujuan menganalisis kelayakan usaha budidaya udang vanname di Keramba Jaring Apung laut. Kajian dilakuan dengan mengunakan metode deskriptif dan analitik dengan jumlah petak keramba yang digunakan sebanyak 18 buah. Kriteria kelayakan usaha yang diamati adalah Net Present Value (NPV), Internal Rate of Return (IRR), Gross Benefit/Cost (B/C) Rasio, Net Benefit/Cost (B/C) Rasio, Pay Back Period (PBP) dan Break Event Point (BEP). Hasil penelitian menunjukkan bahwa nilai NPV sebesar Rp43.315.360; IRR 21.47\%; Gross B/C Rasio 5,11; Net B/C Rasio 3,71; PBP pada 6 bulan 9 hari dan BEP pada produksi udang 1,837.82 $\mathrm{kg}$ atau pada nilai penjualan Rp147.025.891,18. Hasil dari analisis kelayakan usaha budidaya udang vanname di keramba jaring apung laut ini layak untuk dijalankan.
\end{abstract}

Kata kunci: budidaya Udang, kelayakan usaha, keramba jaring apung laut

ABSTRACT

Pacific white shrimp is one of the primadona of fishery commodities. The development of Pacific white shrimp can be done by using floating net cage (FNC). Shrimp culture in sea floating net cage is the one of alternative aquaculture of environmentally friendly shrimp cultivation and potentially become applicative technology of shrimp farming in the future. The aims of this study were to know the feasibility of white shrimp culture in sea floating net cage. The study was conducted by using descriptive and analytic method with 18 pieces of cage. Analysis of the feasibility using net present Value (NPV),Internal Rate of return (IRR), Net Benefit-Cost Ratio, Gross Benefit-Cost Ratio, Payback Period (PBP), and Break Even Point (BEP). The study result show that the NPV is IDR 43,315,360.00; IRR is $21.47 \%$; net $\mathrm{B} / \mathrm{C}$ ratio is 5.11 , gross $\mathrm{B} / \mathrm{C}$ ratio is 3.71 ; $\mathrm{PBP}$ is 6 months and 9 days and $\mathrm{BEP}$ is $1,837.82 \mathrm{~kg}$ of shrimp biomass or IDR $147,025,891.18$ of the value of sales. The final result of feasibility analysis of shrimp culture in sea floating net cage is feasible to run.

Key words: feasibility analysis, sea floating net cage (FNC), shrimp culture

\section{PENDAHULUAN}

Budidaya udang memiliki nilai ekonomis dan prospek pengembangan di masyarakat cukup tinggi yang ditandai dengan semakin meningkat- nya kegiatan budidaya di masyarakat, serta permintaan konsumen, baik masyarakat maupun ekspor yang terus meningkat. Produksi udang secara nasional digunakan untuk mencukupi kebutuhan ekspor. Produksi udang di Indonesia

\footnotetext{
*) Korespondensi:

Politeknik Negeri Lampung, Jl. Soekarno-Hatta No 10. Rajabasa Bandar Lampung; email: pw@polinela.ac.id

Telp : 0721 703995, Hp : +62818259777
} 
pada tahun 2013 mencapai 645 ribu ton atau mengalami peningkatan 19,25\% dibandingkan tahun 2009 sebesar 338 ribu ton (KKP, 2015). Target produksi udang secara nasional terus meningkat untuk memenuhi permintaan ekspor. Pada tahun 2015 produksi udang nasional ditargetkan 785.900 ton, atau meningkat 32\% dari produksi udang tahun 2014.

Budidaya udang selain dilakukan di tambak juga dilakukan di laut/pantai. Budidaya udang putih di laut/pantai menggunakan Keramba Jaring Apung (KJA) pada saat ini belum banyak dilakukan. Budidaya udang dilaut menggunakan keramba jaring apung merupakan salah satu alternatif budidaya udang yang ramah lingkungan dan berpotensi menjadi teknologi aplikatif budidaya udang di masa mendatang dan mengingat potensi laut di Indonesia mencapai 12.123.383 $\mathrm{Ha}$, dimana telah termanfaatkan $325.825 \mathrm{Ha}(\mathrm{KKP}, 2015)$.

Kegiatan pembesaran udang di keramba jaring apung laut masih belum banyak dilakukan karena tingkat keberhasilan yang didapatkan masih ditentukan dari proses kegiatan pemeliharaan dan ketergantungan terhadap alam yang sangat besar. Dengan adanya perkembangan teknologi budidaya udang maka pemanfaatan perairan umum, diharapkan dapat lebih meningkatkan produksi udang nasional. Penggunaan teknologi ini akan berpengaruh terhadap biaya, penerimaan dan keuntungan usahatani. Biaya yang dikeluarkan berupa biaya variabel (variable cost) dan biaya tetap (fixed cost) perlu diketahui untuk menentukan kelangsungan kegiatan usaha budidaya udang di KJA laut

Tujuan kajian ini menganalisis biaya dan pendapatan yang dibutuhkan, serta menganalisis kelayakan usaha pembesaran udang vanname di keramba jaring apung laut.

\section{METODE PENELITIAN}

Kajian dilaksanakan pada unit usaha pembesaran udang vanname di keramba jaring apung laut yang beralamatkan di Desa Hanura, Kecamatan Padang Cermin, Kabupaten Pesawaran. Pelaksanaan kajian kurang lebih selama tiga bulan, yaitu pada bulan Januari-Maret 2018 . Kajian ini menggunakan metode deskriptif dan analitik yang bersifat studi kasus dimana data yang telah terkumpul dideskripsikan sebagaimana adanya menurut hasil produksi.
Analisis kelayakan dilakukan untuk melihat usaha yang dijalankan tersebut layak atau tidak dengan melihat kriteria investasi seperti Net Present Value (NPV), Internal Rate of Return (IRR), Net Benefit/Cost (B/C) ratio, Gross B/C ratio, Payback Period (PBP), dan perhitungan Break Event Point (BEP) yang menjadi dasar perhitungan proyeksi keuangan. Untuk menganalisis kelayakan usaha diperlukan data keuangan. Data yang diperoleh digunakan sebagai dasar perhitungan untuk analisis proyeksi keuangan. Analisis proyeksi keuangan dilakukan dengan metode cash flow.

\section{NPV}

NPV merupakan selisih antara benefit dan cost yang telah diperhitungkan nilainya saat ini pada tingkat bunga tertentu (Ibrahim, 2003). Rumus untuk menghitung NPV adalah:

$$
\mathrm{NPV}=\sum_{t=1}^{n} \frac{b t-c t}{(1+i)^{t}}-k o
$$

\section{Keterangan:}

$$
\begin{array}{ll}
\mathrm{NPV} & =\text { Net Present Value } \\
\mathrm{Bt} & =\text { Benefit/penerimaan tahun } \mathrm{t}(\mathrm{Rp}) \\
\mathrm{Ct} & =\text { Cost/biaya pada tahun } \mathrm{t}(\mathrm{Rp}) \\
\mathrm{I} & =\text { Tingkat bunga }(\%) \\
\mathrm{n} & =\text { Umur ekonomis proyek (Tahun) }
\end{array}
$$

Kriteria pengambilan keputusan :

a. Nilai NPV > 0, maka proyek layak untuk dilaksanakan

b. Nilai NPV $<0$, maka proyek tidak layak untuk dilaksanakan.

c. Nilai $\mathrm{NPV}=0$, maka proyek dalam keadaan titik impas $(B E P)$.

\section{IRR}

IRR merupakan suatu tingkat bunga yang menunjukkan jumlah nilai sekarang netto (NPV) sama dengan jumlah seluruh ongkos investasi proyek. Analisis IRR akan mencari pada tingkat bunga tertentu dengan hasil NPV sama dengan nol. Berdasarkan hasil percobaan, nilai IRR berada antara nilai NPV positif dan negatif, yaitu pada saat NPV sama dengan nol (Ibrahim, 2003). Secara matematik IRR dirumuskan sebagai berikut:

$$
\mathrm{IRR}=i^{+}+\left[\frac{N P V^{+}}{N P V^{+}-N P V^{-}}\right]\left(i^{-}-i^{+}\right)
$$

Keterangan:

$I R R=$ Internal Rate Of Return

$N P V^{+}=N P V$ positif $(\mathrm{Rp})$

$N P V^{-}=N P V$ negatif $(\mathrm{Rp})$

$\mathrm{i}^{+} \quad=$ Tingkat bunga pada NPV positif (\%)

$\mathrm{i}^{-} \quad=$ Tingkat bunga pada $N P V$ negatif $(\%)$ 
Kriteria pengambilan keputusan:

- Bila nilai IRR > i, maka proyek dinyatakan layak untuk diusahakan.

- Bila nilai IRR < i, maka proyek dinyatakan tidak layak diusahakan.

- Bila nilai IRR = i, maka proyek tersebut dalam keadaan titik impas (BEP).

\section{Net B/C Ratio}

Net B/C Ratio merupakan perbandingan jumlah present value penerimaan dengan jumlah present value biaya (Ibrahim, 2003). Net B/C Ratio merupakan perbandingan jumlah nilai bersih sekarang positif dengan jumlah nilai bersih sekarang negatif. Angka ini menunjukkan tingkat besarnya tambahan manfaat pada setiap tambahan biaya sebesar satu satuan. Jika diperoleh nilai net $B / C>1$, maka proyek layak dilaksanakan, tetapi jika nilai $B / C<1$, maka proyek tidak layak untuk dilaksanakan (Gittenger dalam Latifah, 2009). Rumus yang digunakan sebagai berikut:

Net $\mathrm{B} / \mathrm{C}$ ratio $=\frac{\sum_{t=1}^{n} \frac{B t-C t}{(1-i)^{t}}}{\sum_{t=1}^{n} \frac{C t-B t}{(1+i)^{t}}}$

Keterangan:

$\mathrm{Bt}=$ Penerimaan $($ benefit $)$ tahun ke-t $(\mathrm{Rp})$

$\mathrm{Ct}=$ Biaya $(\cos t)$ pada tahun ke- $\mathrm{t}(\mathrm{Rp})$

$\mathrm{I}=$ discount factor $(\%)$

$\mathrm{N}=$ umur proyek (tahun)

Kriteria kelayakan:

a. Bila Net $B / C>1$, maka proyek layak

b. Bila Net $B / C<1$. maka proyek tidak layak untuk dilaksanakan

\section{Gross B/C Ratio}

Gross B/C Ratio adalah perbandingan penerimaan atau manfaat dari suatu investasi dengan biaya yang telah dikeluarkan (Ibrahim, 2003). Rumus yang digunakan adalah:

$$
\text { Gros } \mathrm{B} / \mathrm{C} \text { ratio }=\frac{\sum_{t=1}^{n} B t(1+r)^{n}}{\sum_{t=1}^{n} C t(1+r)^{n}}
$$

Keterangan:

$\mathrm{Bt}=$ Penerimaan (benefit) tahun ke- $\mathrm{t}(\mathrm{Rp})$

$\mathrm{Ct}=$ Biaya $(\cos t)$ pada tahun ke- $\mathrm{t}(\mathrm{Rp})$

$\mathrm{I}=$ discount factor $(\%)$

$\mathrm{N}=$ umur proyek (tahun)

Kriteria penilaian:

a. Bila Gross B/C Ratio > 1, maka proyek layak b. Bila Gross B/C Ratio < 1. maka proyek tidak layak untuk dilaksanakan

c. Bila Gross B/C Ratio = 1, maka proyek dalam Break Event Point

5. PBP

PBP merupakan rasio keuntungan dan biaya dengan nilai sekarang. Jika nilai perbandingan keuntungan dengan biaya lebih besar atau sama dengan 1, proyek tersebut dapat dijalankan (Umar, 1997). PBP merupakan suatu metode yang diperlukan untuk menutup kembali pengeluaran investasi dengan menggunakan aliran kas (Zubir, 2006), dihitung dengan persamaan:

$$
P B P=\frac{\text { Nilai Investasi }}{\text { Kas Masuk Bersih }} \times 1 \text { tahun }
$$

\section{BEP}

BEP adalah tingkat volume penjualan yang menyamakan nilai penjualan dengan total biaya atau laba bersih sama dengan nol. BEP merupakan gambaran kondisi penjualan produk yang harus dicapai untuk melalui titik impas. Proyek dikatakan impas jika jumlah hasil penjualan produknya pada periode tertentu sama dengan jumlah biaya yang ditanggung sehingga proyek tersebut tidak menderita kerugian tetapi juga tidak memperoleh laba (Sutojo dalam Latifah, 2009). Persamaan dalam perhitungan BEP adalah: Total Biaya Tetap

$$
\operatorname{BEP}(\operatorname{Rp})=\frac{}{1-\frac{\text { Biaya Variabel Per unit }}{\text { Harga Jual }}}
$$

\section{HASIL DAN PEMBAHASAN}

Unit pembesaran udang vannamei di KJA laut merupakan sebuah unit usaha milik Politeknik Negeri Lampung yang bergerak dalam bidang budidaya udang vanname yang memanfaatkan perairan umum sebagai lokasi budidayanya. Unit ini mulai beroperasi sejak tahun 2015, dimana lokasi penempatan keramba jaring apung di Desa Hanura Kabupaten Pesawaran. Selain sebagai unit usaha yang dimiliki oleh Politeknik Negeri Lampung, KJA laut juga dimanfaatkan sebagai salah satu lokasi praktik Program Studi Budidaya perikanan untuk mata kuliah Budidaya Air Laut dan Budidaya Udang.

Kontruksi teknologi produksi udang vannamei dengan menggunakan konsep keramba apung bertingkat, dimana jaring luar digunakan sebagai pengaman dari predator liar. Sisa pakan 
dan kotoran dari udang akan langsung ke perairan luas sebagai bahan baku nutrisi pada siklus nitrogen di alam. Pakan yang diberikan diletakkan di anco sebagai feeding area bagi udang (Widigdo, 2007). Pergantian jaring dilakukan menurut kondisi jaring pada saat itu, jika jaring sudah banyak tertutup oleh biofouling yang menempel, maka proses pergantian harus segera dilakukan. Proses pergantian antara 2-3 minggu sekali

Produk yang dihasilkan berupa udang segar yang dipasarkan langsung ke hotel, restoran dan rumah makan maupun masyarakat umum dengan size panen 80-100 ekor per $\mathrm{Kg}$ tergantung dari permintaan konsumen dan harga jual di pasar. Secara periodik, pemanfaatan KJA untuk budidaya udang vanname dilakukan sebanyak tiga siklus per tahun degan lama pemeliharaan dari persiapan sampai dengan panen selama empat bulan. Rataan tingkat kelangsungan hidup yang didapatkan $60 \%$ dari jumlah benur yang ditebar 3000 ekor tiap petak KJA. Peningkatan hasil yang didapatkan terantung dari input produksi yang digunakan, salah satunya adalah kualitas benih. Kagiatan pendederan dengan adanya peningkatan teknologi pemeliharaan terkait tekniknya akan mengikuti hasil kualitas benih yang dihasilkan (Hartono et al., 2017). Salah satu teknik yang digunakan adalah dengan menggunakan sistem bioflok.

Ukuran petak KJA yang digunakan $3 \times 3 \mathrm{~m}^{2}$ dengan jumlah rataan per siklus yang digunakan 18 petak. Hasil panen yang didapatkan rataan berkisar $20 \mathrm{~kg}$ per petak, sehingga dalam satu tahun mampu memproduksi kurang lebih 1.080 kg udang segar dengan harga jual Rp80.000,00 per $\mathrm{kg}$.

\section{Analisis Finansial}

Biaya investasi adalah komponen biaya yang diperlukan untuk memenuhi kebutuhan dana awal pendirian usaha yang meliputi lahan/ areal usaha, peralatan dan sarana produksi. Biaya operasional adalah seluruh biaya yang harus dikeluarkan dalam proses produksi (Witoko et al., 2013). Biaya investasi yang diperlukan meliputi keramba kayu, keramba pencucian jaring, waring mess size 0,8 dan $1 \mathrm{~mm}$, timbangan, anco, jaring panen, basket panen, scoop net, mesin disel, penampungan air tawar, dan perahu kayu. Biaya operasional yang diperlukan meliputi benur udang, pakan udang, obat obatan, vitamin, bahan bakar, biaya panen, tenaga kerja dan perawatan

Total investasi awal yang dikeluarkan Rp45.300.000. Dengan umur pakai rataan selama lima tahun maka didapatkan biaya penyusutan Rp9.060.000. Total biaya operasional yang dibutuhkan selama setahun kegiatan produksi Rp54.420.000. Total biaya keseluruhan yang dikeluarkan selama setahun Rp63.480.000. Penerimaan total unit usaha pembesaran udang vanname dalam rentan satu tahun Rp86.400.000, didapatkan nilai keuntungan per tahun sebesar Rp22,920,000.

\section{Kelayakan Usaha}

Evaluasi profitabilitas rencana investasi dilakukan dengan menilai kriteria investasi untuk mengukur kelayakan usaha, yaitu meliputi NPV, IRR, Net B/C Ratio, Gross B/C Ratio, PBP, BEP. Hasil perhitungan kelayakan usaha pembesaran udang vanname di Keramba Jaring Apung laut dilihat pada Tabel 1.

Usaha pembesaran udang vanname di KJA laut dengan pemilihan pola usaha dan menggunakan asumsi yang ada menghasilkan NPV Rp43.315.360. Hasil tersebut menunjukkan bahwa nilai yang dihasilkan lebih besar dari 0 (nol), sehingga dikatakan usaha tersebut feasible untuk dilaksanakan. Jika nilai $\mathrm{NPV}=0$, maka usaha tersebut dalam keadaan BEP. Pada tingkat suku bunga 14\% didapatkan nilai IRR 21,47\%, karena nilai yang didapatkan IRR lebih besar dari nilai diskon faktor, hal ini menunjukkan bahwa

Tabel 1. Kelayakan usaha budidaya Udang Vanname di KJA laut

\begin{tabular}{cccc}
\hline No & Kriteria & Nilai Justifikasi & Kelayakan \\
\hline 1. & NPV (Rp) & 43.315 .360 & $>0$ \\
2. & IRR (\%) & 21,47 & $>14$ \\
3. & Gross B/C Ratio & 5,11 & $>1,00$ \\
4. & Net B/C Ratio & 3,71 & $>1,00$ \\
5. & PBP & 0,524 tahun & 6 bulan 9 hari \\
6. & BEP & & \\
& $(\mathrm{Kg})$ & $1.837,82$ & \\
\hline & Rp) & $147.025 .891,18$ & Layak \\
\hline
\end{tabular}


usaha dibidang produksi udang vannamei layak dilakukan. Hal tersebut menunjukkan bahwa persentase IRR lebih dari 0 (nol). Gross B/C Ratio 5,11 dan Net B/C Ratio 3,71 memiliki nilai > 1 berarti cash in flows lebih besar dari pada cash out flows atau total revenue lebih besar daripada total cost atau dengan kata lain setiap satu rupiah pengeluaran atas biaya tunai akan memberikan penerimaan Rp5,11 dan Rp3,71. Berdasarkan kriteria dan asumsi yang ada menunjukkan usaha pembesaran udang vanname di KJA laut dengan skala minimal yang dipilih ini sudah layak untuk dilaksanakan dengan PBP selama 0,524 tahun atau 6 bulan 9 hari, berarti bahwa dalam kurun waktu tersebut total cost yang dikeluarkan sama dengan total revenue yang diterima. BEP usaha pembesaran udang vanname berada pada produksi udang 1.837,82 $\mathrm{kg}$ atau pada nilai penjualan Rp147.025.891,18, berarti pada nilai tersebut suatu usaha dapat dikatakan kembali modal.

\section{KESIMPULAN}

Analisis kelayakan usaha pembesaran udang vanname di KJA laut dikatakan layak, karena hasil perhitungan yang dilakukan memberikan manfaat secara financial, hasil perhitungan dengan kebutuhan biaya investasi Rp45.300.000,00 dan rataan biaya operasional setiap tahun Rp54.420.000,00 menghasilkan nilai NPV Rp43.315.360,00., IRR 21,47\%, Gross B/C Ratio 5,11, Nett B/C Ratio 3,71, PBP selama 0,524 tahun atau 6 bulan 9 hari dan BEP pada produksi udang $1.837,82 \mathrm{~kg}$ atau pada nilai penjualan Rp147.025.891,18.

\section{DAFTAR PUSTAKA}

KKP, 2015. Budidaya Udang Vannamei (Litopenaeus vannamei) Pola Tradisional Plus.Jurnal Kelautan dan Perikanan. Jakarta.

Hartono, D.P., P. Witoko, dan N. Purbosari. 2016. the Effect of Heat Shock on the Tetraploidy of Catfish (Pangasius hypophthalmus). Aquaculture, aquarium, conservation and legislation-International Journal of the Bioflux Society (AACL Bioflux), 9(3): 597603.

Ibrahim, Y. 2003. Studi Kelayakan Bisnis (edisi revisi). PT. Rineka Cipta, Jakarta.

Latifah, E., A. Suryani dan H. Hardjomidjojo. 2009. Analisis Kelayakan Pembiayaan Pengembangan Usaha Mebel Kayu pada Bank Syariah (Studi Kasus: PT. "X" di Bekasi). Jurnal MPI, 4(1): 57-74.

Umar, H. 1997. Studi Kelayakan Bisnis, Gramedia Pustaka Utama, Jakarta.

Widigdo, B. 2007. Good Aquaculture Practice, Gap Penerapan Kaedah Budidaya Secara Baik dan Benar. Integrated Quality Assurance Division, PT CP. Bahari. Lampung.

Witoko, P., R. Syarief, dan S. Raharja. 2013. Kelayakan dan Strategi Pengembangan Usaha Pembenihan Ikan Patin di CV. Mika Distrindo. Jurnal Manajemen IKM, 8(2): 115-122.

Zubir, Z. 2006. Studi Kelayakan Usaha. Lembaga Penerbit Fakultas Ekonomi Universitas Indonesia, Jakarta. 